\title{
Recurrent Abdominal Pain in Peutz-Jeghers Syndrome: A Case Report
}

\author{
S ANWAR ${ }^{\mathrm{a}}, \mathrm{N} \mathrm{KAMAL}^{\mathrm{b}}, \mathrm{R} \mathrm{KHANOM}^{\mathrm{c}}$, $\mathrm{SK}^{\mathrm{ROY}}{ }^{\mathrm{d}}, \mathrm{F} \mathrm{KABIR}^{\mathrm{e}}, \mathrm{R} \mathrm{SHHA}^{\mathrm{f}}$
}

\begin{abstract}
Summary:
Peutz-Jeghars Syndrome (PJS), also known as peri-orificial lentiginosis, is a condition of autosomal dominant inheritance. Here, mutation localized at (19p13.3) LKB1/ STK11. It is characterized by presence of mucocutaneous pigmentation and gastrointestinal (GI) hamartomatous polyps. This case of PJS, is a 7 year old girl who came with recurrent vomiting and abdominal pain for 1 year and weight loss for 8 months. She had multiple black pigmentation over lips and buccal mucosa. Endoscopy revealed multiple polyps in stomach and duodenum.
\end{abstract}

\section{Introduction:}

Y.Peutz, a Dutch paediatrician, describes in 1921, a family with skin pigmentation and polyps of the small bowel. Similar cases were reported in US by H.Jeghars and colleagues in 1949 and consequently the name of Peutz-Jeghars Syndrome (PJS) was adopted for this disorder. It is an autosomal dominant inherited condition although in $50 \%$ cases there might be spontaneous mutation. Diagnosis is based on clinical findings and histopathological patterns of polyps. It is associated with significant morbidity due to risk of both intestinal and extra intestinal malignancies. Most patients have a characteristic clinical course of recurrent episodes of polyp induced bowel obstruction and bleeding.

a. Prof. Dr. Sayeeda Anwar, Professor and Head of Department of Paediatrics, Dhaka Medical College and Hospital.

b. Dr. Nusrat Kamal, Indoor Medical Officer, Department of Paediatrics, Dhaka Medical College and Hospital.

c. Dr. Rokeya Khanom, Associate Professor, Department of Paediatrics, Dhaka Medical College and Hospital.

d. Dr. Subrota Kumar Roy, Assistant Professor, Department of Paediatrics, Dhaka Medical College and Hospital.

e. Dr. Farzana Kabir, Assistant Registrar, Department of Paediatrics, Dhaka Medical College and Hospital.

f. Dr. Ramkrishna Saha, Indoor Medical Officer, Department of Paediatrics, Dhaka Medical College and Hospital.

Address of Correspondence: Prof. Dr. Sayeeda Anwar, Professor and Head of Department of Paediatrics, Dhaka Medical College and Hospital. Mobile: 01819229423,E-mail: anwarsayeeda@yahoo.com

Received: 25 April, 2018

Accepted: 3 January, 2019
Besides supportive management, polyps were removed by surgical intervention. Biopsy of these polyps showed hamartomatous type. Post operative period was uneventful. She recovered well. So far there was no recurrence of pain. She is on regular follow up.

Key words: Hyperpigmentation, mucocutaneous polyp, recurrent abdominal pain, recurrent vomiting

(J Bangladesh Coll Phys Surg 2019; 37: 160-164)

DOI: https://doi.org/10.3329/jbcps.v37i3.41739

Melanic spot typically appear in $1^{\text {st }}$ year of life. Lesion can fade by puberty or adulthood. There are multiple rarely 20 hamartomatous polyps present in GI tract, primarily found in small intestine ${ }^{1}$.The size of Polyp varies. Risk of dying from a GI cancer is 13 times greater and risk of extra-intestinal cancer especially cancer of reproductive organ, breast, pancreas and lung is 9 times greater than in general population ${ }^{2}$. The Johns Hopkins University reported a $48 \%$ incidence of cancer with $73 \%$ rising in gastrointestinal tract ${ }^{3}$. Early detection and proper evaluation and surveillance are vital to minimize the risk of malignancies. This case was reported because though clinical presentation of PJS is rare in this age group but it should be a differential diagnosis of recurrent abdominal pain.As there is risk of development of both intestinal and extra intestinal malignancy,such cases should be thoroughly evaluated.

\section{Case Report:}

Ashamoni, a 7-year-old immunized girl, $2^{\text {nd }}$ issue of non-consanguineous parent hailing from chuadanga got admitted to Dhaka Medical College Hospital (DMCH) on $9 / 11 / 2016$ with the complaints of recurrent abdominal pain and vomiting for 1 year and gradual weight loss for 8 months. Initially pain was around the umbilicus, later spread over the whole abdomen. Pain was colicky in nature, non-radiating, aggravated by taking food or water and relieved by vomiting or antispasmodic drug. Vomiting was present for same duration along with pain which contained undigested food particles. She had no history of headache, fever, 
convulsion, cough, jaundice, abdominal distension, contact with TB patient or taking any offending drugs. Her bladder habits was normal. She had no family history of such type of illness. With these complaints she was treated with several medications and underwent appendectomy 8 months back without any improvement. With these complaints she got admitted to DMCH on $9 / 11 / 2016$. Clinically, the child was ill looking, mildly pale. Vital parameters were within normal limit. Her height was $117 \mathrm{~cm}$, weight was 14 $\mathrm{kg}$, and BMI was $10.21 \mathrm{~kg} / \mathrm{m}^{2}$ which falls below 5th percentile. BCG mark was present. There were multiple black pigmented macules on mucosa of lip, right side of upper gum opposite to molar teeth and inner part of upper jaw(Fig.-1). Examination of abdomen revealed normal. On investigation, Hb was $10.2 \mathrm{~g} / \mathrm{dl}$, WBC count was $9000 / \mathrm{cmm}$, Total and differential count were
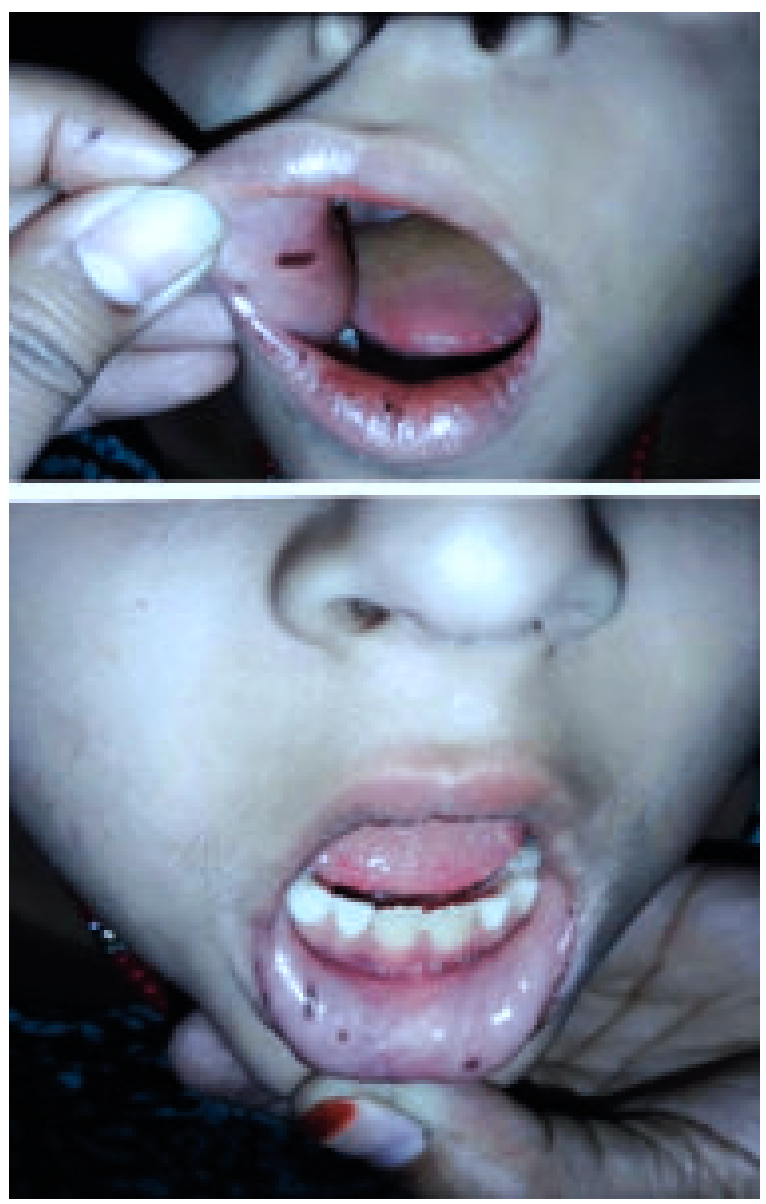

Fig.-1: Typical brown macules on lips and oral mucosa within normal limit, ESR was $40 \mathrm{~mm}$ in $1^{\text {st }}$ hour. PBF shows mild microcytic hypochromic anemia. Serum electrolyte, S.ALT, S.Amylase, S. Lipase, Stool R/M/ E, random Blood Glucose were normal. Occult blood test was negative. . Chest X-ray was also normal. Barium meal follow through shows gastric stasis probably due to duodenal stricture (Fig.-2). Endoscopy revealed multiple pedunculated (Cauliflower like) both gastric and duodenal polyps (Fig.-3). Colonoscopy was normal. Gastric polyps were removed endoscopically and duodenal one by laparotomy (Fig.-4) by pediatric surgeons and sent for histopathological study which showed hamartomatous in origin( Fig.-5).The patient was advised for regular follow up for early detection of any type of complication.

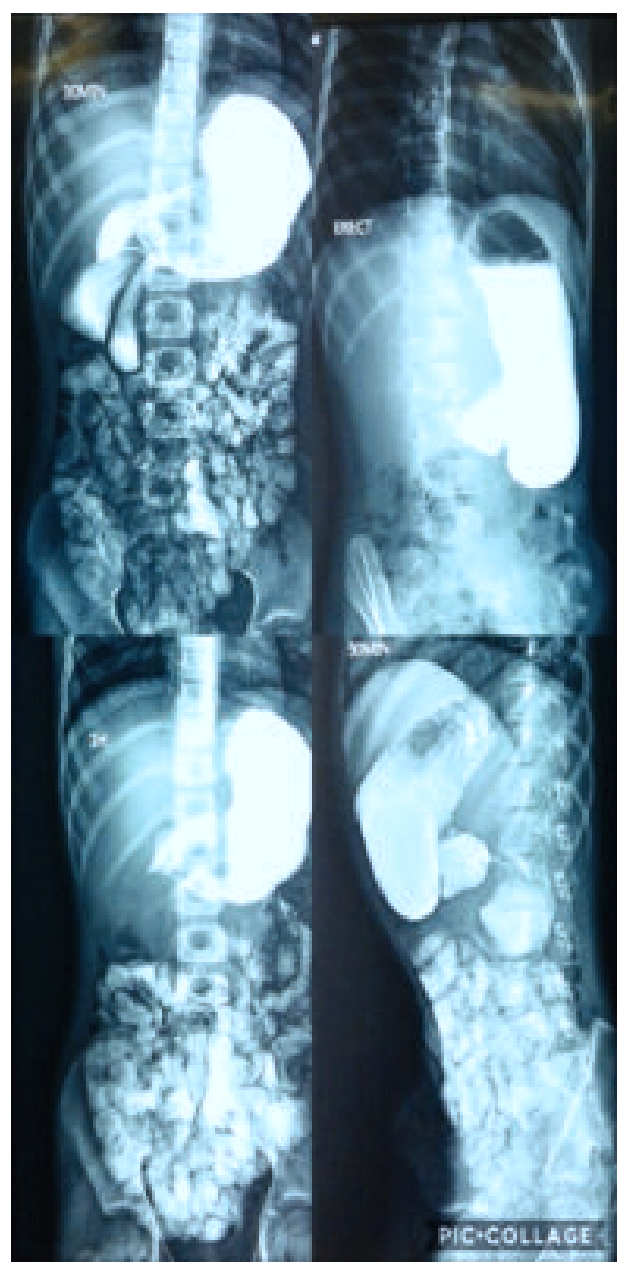

Fig.-2: Barium meal follow through studies shows gastric stasis due to stricture. 

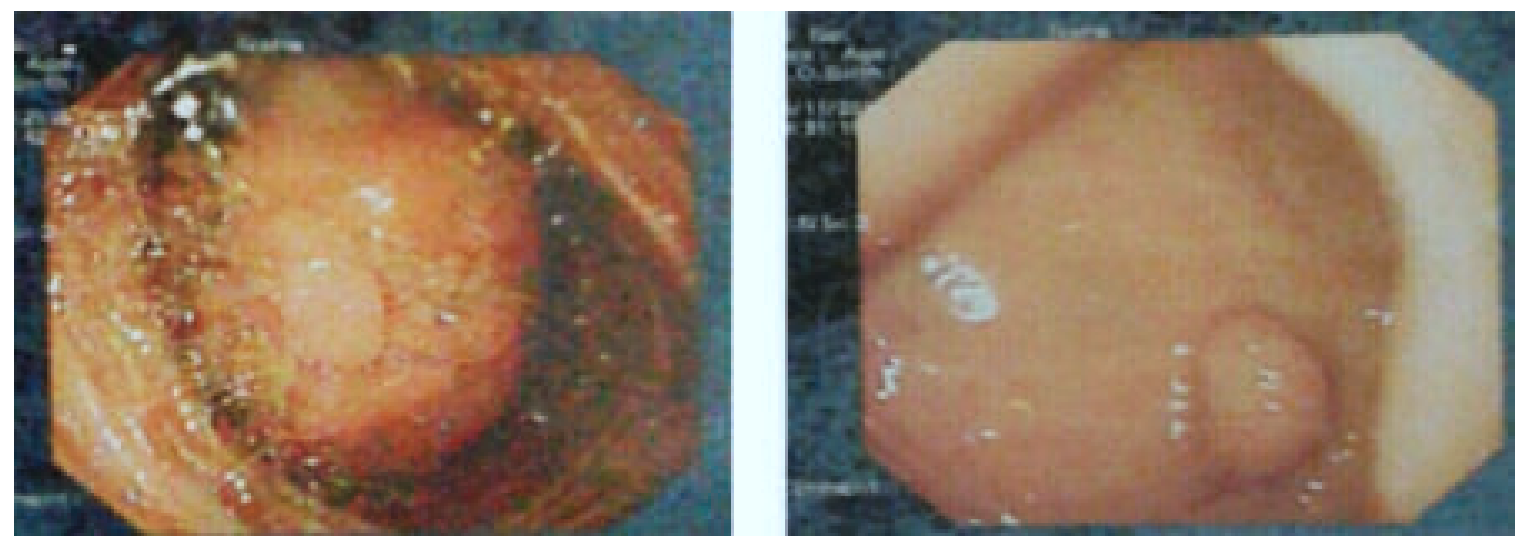

Fig.-3: Endoscopic view of small intestinal (Duodenal) polyp

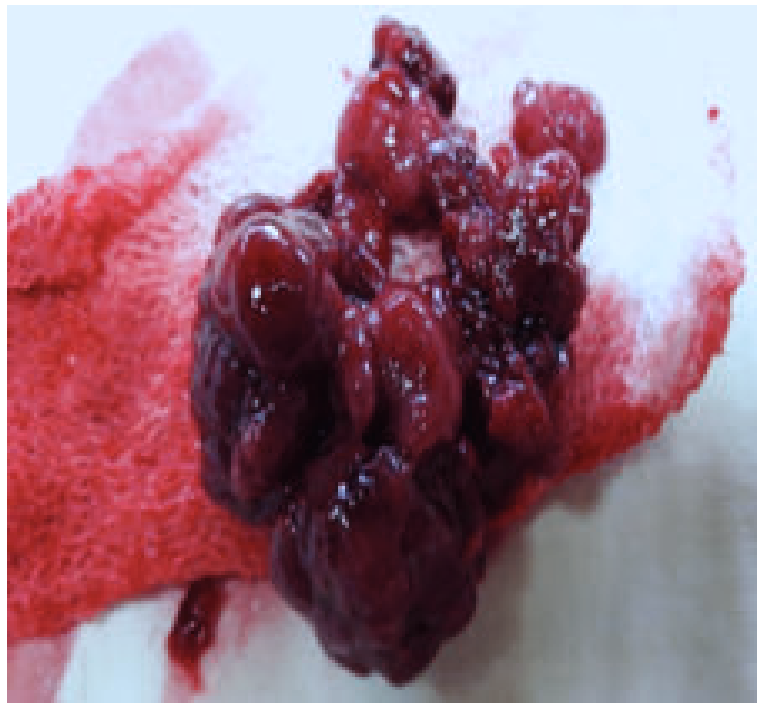

Fig.-4: Multiple pedunculated (Cauliflower like) polyps

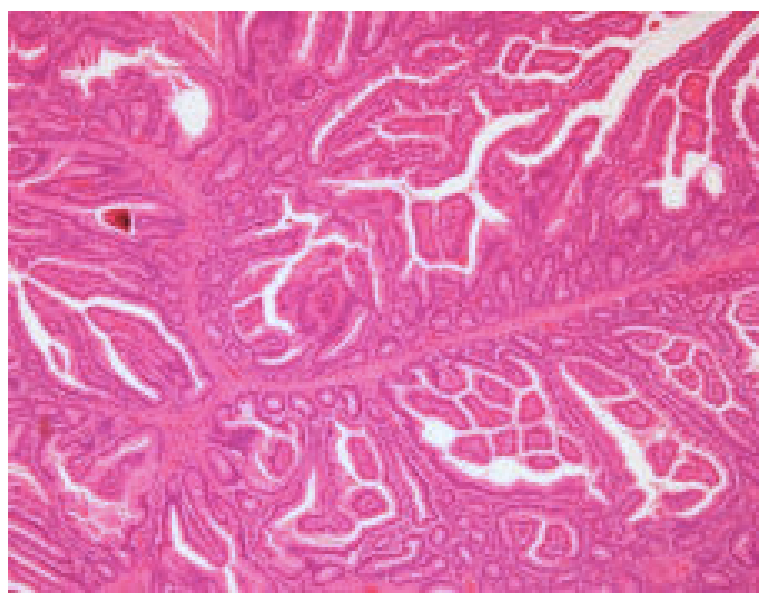

Fig.-5: Histopathology of a duodenal polyp of hamartomatous origin; HE stain (objective 10x)

\section{Discussion:}

PJS is characterized by mucocutaneous pigmentation and GI hamartomatous polyp ${ }^{4,5,6}$. Estimated incidence is 1 in 120000 live birth ${ }^{7}$. It has no racial or sexual predilection ${ }^{8}$.

PJS belongs to hamartomatous polyposis syndrome which are a heterogeneous group of disorder inherited in an autosomal dominant manner. Apart from PJS, these syndrome includes juvenile polyposis syndromes and phosphate and tensin homologue deleted in chromosome ten (PTEN) hamartomatous syndrome (PHTS). PHTS includes Cowden syndrome, BannayanRiley-Ruvalcaba syndrome and all syndromes in which there are germline PTEN mutation.

.The mutant gene is serine threonine kinase (STK11/ also known as $\mathrm{LKB} 1)^{8,9,10}$. It is located at $19 \mathrm{p} 13 \cdot 3^{8,9,10}$. STK11 protein is involved in the inhibition of AMPactivated protein kinase (AMPK) and signals downstream to inhibit the mTOR pathway. The mTOR pathway seems to be dis regulated in patient with PJS.

The hyper pigmented lesion contain melanotic deposits which commonly manifest in infancy and childhood. Pigmented lesion can fade during puberty and adulthood $^{6}$. It may be dark brown to dark blue in colour. Size may vary from 1 to $12 \mathrm{~mm}$. They are primarily found around the lips and oral mucosa, although these lesion may also be found on hands, feet or perineum, conjunctiva or rectum ${ }^{11}$. When the melanotic spots are localized on the face, the diameter rarely are larger than $2 \mathrm{~mm}^{5,6,12}$.

The polyps are main characteristic and they could vary in their shape, size, number and anatomical distribution. 
Most commonly found in small intestine, but they can occur anywhere from stomach to rectum. The median time to first presentation with polyps is about 11-13 years of age and approximately $50 \%$ will have experienced symptoms by the age of 20 years $^{(7)}$. ThePeutz-Jeghers polyp varies in size from $<1 \mathrm{~cm}$ to $>3.5 \mathrm{~cm}$ in diameter, and may be pedunculated or sessile. This polyp is generally considered a hamartomatous polyp but with an abnormal growth pattern. The most characteristic feature of a PeutzJeghers polyp is a central core of smooth muscle that extends into the polyp in an arborizing fashion (Christmas tree like appearance). Some polyp may turn into Adenomatous or carcinomatous transformation ${ }^{13}$. Complications induced by polyps include colicky abdominal pain, bleeding, and bowel obstruction due to intussusception. The time when abdominal symptoms commence can vary. They may present as early as the first year of life or at the age of 40 years ${ }^{14}$. By the age of ten years, $30 \%$ of patients with PJS already required a laparotomy ${ }^{15}$.

The diagnosis of PJS is established by the presence of histopathologically confirmed hamartomatous polyps and at least two of three clinical criteria:

a family history of PJS, the presence of mucocutaneous pigmentation and the presence of small-bowel polyps $^{16}$.

Our patient has 2 out of 3 diagnostic criteria: mucocutaneous pigmentation small bowel polyp along with histologically proven hamartomatous polyp.

Important imaging features of Peutz-Jeghers syndrome consist of multiple polypoid lesions and intussusception. Polyps can be detected with endoscopy, colonoscopy, barium studies, ultrasonography (USG) or computed tomography (CT). Some authors have suggested using US or magnetic resonance (MR) imaging for follow-up imaging to reduce the lifetime radiation burden ${ }^{17}$.

Treatment option for Peutz-Jeghers syndrome include laparotomy and bowel resection to remove symptomatic gastrointestinal polyps that cause persistent or recurrent intussusceptions. This has been done over the years but lead to short gut syndrome. During each laparotomy, the small bowel should be examined by means of intraoperative enteroscopy
(IOE). Nowadays, double balloon enteroscopy (DBE) in combination with capsule enteroscopy are the gold standard for the diagnosis and treatment of the small bowel hamartomatous polyps ${ }^{5}$. Recently, intraoperative endoscopy and endoscopic polypectomy rather than segmental resection of the bowel have been recommended. The new mouth to anus (M2A) capsule endoscopy will probably become the most useful screening tool in the near future.

Some expert suggest that an attempt to clear the small intestine of polyps ("clean sweep") should be made during laparotomy.It decreases the need for recurrent small bowel surgery 6,7 . It is even possible to treat benign hyperpigmentation of the face by means of laser therapy. Q-switched lasers are the preferred method. The treatment is only as cosmetic purpose ${ }^{4}$.

\section{Conclusion:}

Patients with PJS should be regularly and closely monitored because of increased risk of cancer and to reduce the number of laparotomies. Periodic endoscopic screening are advocated every 2 year for 25 year. Screening at-risk individuals (first-degree relatives of PJS patients) should begin at birth and annual history and physical examination with evaluation for melanotic spots, precocious puberty and testicular tumours is highly recommendable. At-risk individuals who are asymptomatic and without stigmata at age 8 years should be offered genetic testing for mutation of the STK11/LKB1 gene.

\section{References:}

1. Tomlinson IP, Houlston RS. Peutz-Jeghers syndrome. J Med Genet 1997; 34(12): 1007-11.

2. Spigelman AD, Murday V, Phillips RK. Cancer and the PeutzJeghers syndrome. Gut 1989; 30 (11): 1588-90.

3. Fenoglio-Preiser C. Polyposis syndromes. In: Fenoglio - Preiser C, Lantz PE, Listrom MB, Davis M, Rilke FO. Gastrointestinal Pathology. An atlas and Text. 2ed. Philadelphia: Lippincott Raven publish- ers; 1999.p. 717-45

4. Georgescue F, Stanescu L, Simionescu C, Georgescue I, Ionescu R, Florescu G, et al. Peutz- Jeghers syndrome: case report and literature review. Romanian J Morphol Embryol 2008, 49(2): 2415.

5. Li Y, Zeng Q, Liao Z, Zhang G, Xiao R, Wen H. Peutz-Jeghers syndrome and family survey: a case report, Int J Clin Exp Pathol 2013; 6(5): 982-4.

6. Hafeez AA, Dahan A, Yasin MAK. Peutz-Jeghers Syndrome presented as intermittent gastric outlet obstruction and ileoileal intussusceptions. Sudan J Med Sci 2012; 7(2): 131-4. 
7. Kliegman, Stanton, St Geme, Schor .Nelson Textbook of PEDIATRICS, $20^{\text {th }}$ edition; volume-2; p-1902.

8. ISLAM MR, HOSSAIN MS, SHEIKH MSH,RAHMAN MR,LIMAIJ, KHATUN SA,KASHEM MA,et al. Peutz-Jeghers syndrome:A case report and literature review. J Dhaka Med Coll. 2014;23(1): 147-150.

9. Amos CI, Bali D, Thiel TJ, Anderson JP, Gourley I, Frazier ML, et al. Fine mapping of a genetic locus for Peutz-Jeghers syndrome on chromosome 19p. Cancer Res 1997; 57 (17): 3653-6.

10. Braun Falco O, Plewig G, WalffHH, BurgdorfWHC. Dermatology: Springer, Berlin 2000; 1515-6.

11. Marcela Kopacova, Ilja Tacheci, Stanislav Rejchrt, Jan Bures. Peutz-Jeghers syndrome: Diagnostic and therapeutic approach. WorldJGastroenterol2009November21;15(43):5397-5408.

12. Gazozai S, Sadiq S. Pautz-Jegher Syndrome: case report and review of literature. Biomedica 2005; 21.
13. Karl H. Perzin, Mary F. Bridge, Adenomatous and Carcinomatous Changes in Hamartomatous Polyps of the Small Intestine (PeutzJeghersSyndrome):Cancer1982;49:971-983.

14. Fernandez Seara MJ, Martinez Soto MI, Fernandez Lorenzo JR, Trabazo S, Gamborino E, Forteza. Vila J. Peutz-Jeghers syndrome in a neonate. J Pediatr 1995; 126 (6): 965-7.

15. Hinds R, Philp C, Hyer W, Fell JM. Complications of childhood Peutz-Jeghers syndrome: implica- tions for pediatric screening. J Pediatr Gastroenterol Nutr 2004; 39 (2): 219-20

16. Giardiello FM, Welsh SB, Hamilton SR, Offerhaus GJ, Gittelsohn AM, Booker SV, et al. Increased risk of cancer in the PeutzJeghers syndrome. N Engl J Med 1987; 316 (24): 1511-4.

17. Kurugoglu S, Aksoy H, Kantarci F, et al. Radiologic work-up in Peutz-Jegherssyndrome.PediatrRadiol2003;33:766-771.

18. FRANCIS M. GIARDIELLO, JILL D. TRIMBATH et al. Peutzjeghers Syndrome and Manassgement Recommendations. CLINICAL GASTROENTEROLOGYAND HEPATOLOGY 2006; 4:408-415. 